\title{
Open Letter To
}

\author{
The Honourable Flora MacDonald \\ Minister, Canada Employment \& Immigration Department
}

\section{Dear Miss MacDonald:}

Let me congratulate you on your re-election and on your appointment as Minister of Employment \& Immigration.

As recently re-appointed NDP critic for Immigration I consider you a good choice. In the past you have expressed compassion for human rights concerns and sensitivity to those oppressions or misfortunes outside Canada that create desperation for millions of refugees and other migrants. I trust that you will let this compassion and understanding guide your judgements as you and your government develop immigration policy for Canada.

I write also today on some matters I wish you may consider during the coming months.

Overall, I believe we must continually try to avoid making refugees and immigrants scapegoats for unemployment in Canada. This can be a tempting excuse. Scapegoating immigrants is unjust, because the evidence has never been accumulated to prove that immigrants aggravate unemployment; it creates distress among many Canadians including immigrants; and it too of ten allows us to underrate legitimate humanitarian concerns.

One example of this scapegoating was the "temporary freeze" imposed May 1, 1982 on all independent class immigrants who did not have approved job offers. Because the assisted relative class is part of the independent class, this regulation means that sons and daughters over 21 have little hope of being re-united. That decision really hurt. It needs review and revision.

The August announcement on streamling the "last remaining family member" applications has helped, but it is only a beginning. We need to be compassionate to end the pain of separated families.

Closely related is that section of I.S. 1:39 that allows husbands and wives to sponsor spouses while the spouses being sponsored resides in Canada. I understand reviews have been done internally but there has been no published report to discuss. It appears that I.S. 1:39 does allow for this kind of sponsorsheip on a case by case basis and under specific criteria - but it also appears that immigration officials interpret these guidelines inconsistently and, over the months, with less and less favour to the applicants.

Again, under I.S. 1:39 (de facto residence), our experience with the Long-Term Illegal Migrants Program has been frustrating. I hope the "third party" or "anonymous" case by case review with a central committee to ensure uniformity can continue. In any case I ask you to meet with a coalition of churches and community groups from the Toronto area who are actively concerned about illegal migrants and their families. They tried for a year to meet with your predecessor.

Another temptation has been to abuse the visa requirement so as to prevent the making of refugee claims within Canada. While there was very little abuse by applicants from countries like Chile and Guatemala before the visa requirement was imposed, such requirement has made the most urgent requests for refugee consideration very, very difficult. Canda ought not to use the visa as a way of avoiding refugee hearings.

Our general refugee review process still has many prblems: delays, sometimes poor knowledge of the political and economic circumstances in the home country, and an awkward procedure. Oral hearings have been recommended time and time again. No doubt Rabbi Plaut will again make this recommendation. There is no point in more studies. It is time to establish oral hearings and many of the other recommendations made to humanize and give justice to refugee applicants in Canada.

I trust you will be a sincere and good Minister. I offer the above as advice based on my three years of work in this area with the public and your staff. I would be glad to meet with you to discuss them or any other issue related to the portfolio.

Yours very truly

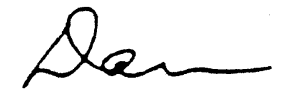

Dan Heap, M.P. Spadina 